\title{
Working ability after cardiovascular events or procedures
}

\author{
Zdravko Babićc ${ }^{*}$, Vjeran Nikolić Heitzler ${ }^{1}$, Davor Miličićc ${ }^{2}$ Bojan Biočina ${ }^{2}$, Robert Bernat ${ }^{3}$, \\ Duško Cerovec ${ }^{4}$ \\ 'University Hospital Centre "Sestre milosrdnice", Zagreb, Croatia \\ ${ }^{2}$ University of Zagreb School of Medicine, University Hospital Centre Zagreb, Zagreb, Croatia \\ ${ }^{3}$ Special Hospital Magdalena, Krapinske Toplice, Croatia \\ ${ }^{4}$ Special Hospital Krapinske Toplice,Krapinske Toplice, Croatia
}

In demanding modern times with population aging, low natality, delayed start of the work, and extension of working lifetime, the working activity in cardiovascular diseases has become a very important issue. Modern guidelines have shortened period of return to work after acute myocardial infarction (AMI) to 1-3 months (50 days-median in the most countries) while some authors, especially in USA, consider that return to full normal activities, including work, at 2 weeks after AMI appears to be safe in low-risk patients (pts). Inadequate health policy and delayed cardiac rehabilitation after AMI may lead to prolonged hospitalization and sick leave, as well as quality of life lowering, regardless of optimal treatment in acute phase of disease. Hospital readmission in 6 months and mortality in 5 years could be expected in $50 \%$ of heart failure (HF) pts. Many studies revealed the positive effect of exercise training on risk of death in those pts. Left ventricular ejection fraction (LVEF) is one of the most important factors that determine the working ability in HF pts: LVEF $40-49 \%$ enables moderate workload, 30-39\% low workload, $20-29 \%$ only sedentary works, and $<20 \%$ no works. The USA Social Security regulations approve for disability pts after ECG proven arrhythmias caused with irreversible conditions and followed with syncope or presyncope despite the recommended treatment on at least three different occasions in 12 consecutive months. Individual evaluation of permanent vs. transient working inability depending of type of arrhythmia or working place, symptoms and basic disease should be emphasized. Working ability recovery after cardiac surgery is determined with recovery of different organs and organic systems: skeletal (up to 6 weeks), respiratory (1-30 days), visceral (up to 7 days), neurological (1 day-permanent) and heart (depending on a type of work and individual pts. characteristics, on the average 48 weeks). Different activities should be restarted gradually. Suggested non-driving period after cardiovascular events or procedures is different for private and commercial vehicles. After AMI for a private one the non-driving period is 2 and for a commercial vehicle the non-driving period is 4 weeks, after percutaneous coronary interventions 2 days and 4 weeks, and after aorto-coronary by-pass surgery it is 4 weeks and 3 months respectively. After cardiac arrest 6 months of nondriving period is recommended for the both groups of drivers, while ICDs, unlike pace-makers, are not applicable in commercial vehicle drivers.

KEYWORDS: working ability, cardiovascular diseases. CITATION: Cardiol Croat. 2013;8(9):318.

$20^{\text {th }}$ Jun 2013

*Address for correspondence: Klinički bolnički centar "Sestre milosrdnice", Vinogradska 29, HR-10000 Zagreb, Croatia.

Phone: +385-98-383-639

E-mail: zbabic@net.hr

\section{Literature}

1. Alegria-Ezquerra A, Grima A. Reporting on coronary patients for return to work: an algorithm. E-journal of the ESC Council for Cardiology Practice. 2012;10(20). http://www.escardio.org/communities/councils/ccp/e-journal/volume10/Pages/cardiovascular-risk-functional-capacity-coronary-patients-return-to-work-Grima-AlbertoAlegr\%C3\%ADa-Eduardo.aspx\#.Uh5SJWS9-SQ (20. 6. 2013.).

2. Schwaab B. Cardiovascular rehabilitation. Internist. 2010;51:1231-2.

3. Cerovec D, Lakušić N, Baborski F, Fučkar K, Slivnjak V. Cardiac rehabilitation efficacy and cost effectiveness. Cardiol Croat. 2012;7(Suppl 1):106-7. 